\title{
Território e rede, inovação e desenvolvimento. A formação tecnológica em questão
}

Territory and network, innovation and development. The technological

formation in question

Territoire et réseau, innovation et développement. La formation technologique en question

Territorio y red, innovación y desarrollo. La formación tecnológica en cuestión.

\section{Artur Sérgio Lopes}

\section{(2) OpenEdition}

Journals

Edição electrónica

URL: https://journals.openedition.org/espacoeconomia/21370

DOI: 10.4000/espacoeconomia.21370

ISSN: 2317-7837

\section{Editora}

Núcleo de Pesquisa Espaço \& Economia

\section{Refêrencia eletrónica}

Artur Sérgio Lopes, «Território e rede, inovação e desenvolvimento. A formação tecnológica em questão», Espaço e Economia [Online], 22 | 2021, posto online no dia 14 janeiro 2022, consultado o 11 agosto 2022. URL: http://journals.openedition.org/espacoeconomia/21370 ; DOI: https://doi.org/ 10.4000/espacoeconomia.21370

Este documento foi criado de forma automática no dia 11 agosto 2022.

\section{cc) (†) (ㅇ)}

Creative Commons - Atribuição-NãoComercial-Compartilhalgual 4.0 Internacional - CC BY-NC-SA 4.0 https://creativecommons.org/licenses/by-nc-sa/4.0/ 


\section{Território e rede, inovação e desenvolvimento. A formação tecnológica em questão}

Territory and network, innovation and development. The technological

formation in question

Territoire et réseau, innovation et développement. La formation technologique en question

Territorio y red, innovación y desarrollo. La formación tecnológica en cuestión.

\section{Artur Sérgio Lopes}

\section{Introdução}

1 A presente comunicação aborda a construção de plano de investigação e estudos referente aos nexos entre a configuração da rede pública de formação tecnológica e os processos e políticas em torno do desenvolvimento em âmbito regional/local. Identifica-se o significado atribuído a essas unidades de ensino como potenciais vetores de desenvolvimento (SOUZA, 2019) e polos de inovação. As formulações a serem apresentadas derivam de inquietações desenvolvidas a partir da atividade docente na Faculdade de Educação Tecnológica do Estado do Rio de Janeiro (FAETERJ), campus Paracambi, nos cursos de Tecnólogo em Gestão Ambiental e Tecnólogo em Sistema da Informação. Tais formulações vinculam-se à agenda de debates e reflexões no âmbito do grupo de estudos Redes Técnicas e Linhas Cruzadas e o Núcleo de Pesquisas em Espaço e Economia, Universidade do Estado do Rio de Janeiro (NUPEE - UERJ).

2 Trata-se de estudos e pesquisas que sinalizam uma geografia sobre a rede de formação tecnológica (pressupostos e políticas que a constituem) diante da configuração do mundo do trabalho, da inovação e do desenvolvimento em seus processos e expressões no território - suas densidades e redes; como também sobre o estudante, não 
exclusivamente jovem, que vivencia sua condição e perspectivas de futuro, por via da formação tecnológica.

3 Além dessa introdução e das considerações não propriamente finais, o exposto nesta comunicação tem como ponto de partida os significados e contextos que embasam a geografia que se enseja, o que atribui sentido de concretude e representação. Refere-se ao lugar em que se situa a FAETERJ Paracambi - a antiga fábrica têxtil que hoje é designada como Fábrica do Conhecimento, o que remete ao regional que se constituí mediante a histórica do território e da técnica. A partir daí, delineamentos teóricometodológicos referentes à correspondência entre os conceitos de território e redes técnicas se fazem necessários: categorias analíticas que imprimem lastros investigativos aos estudos e pesquisas em construção. Posteriormente, são expostas compreensões sobre a problemática referente às possibilidades e entraves presentes na formação tecnológica. Em seguida, abordam-se as perspectivas analíticas referentes à correspondência entre desenvolvimento e inovação. Ambas compreensões e perspectivas embasam as pesquisas e estudos em desenvolvimento nessa agenda, o que, por fim, é exposto por meio de breve apresentação sobre as aproximações e percursos em andamento.

\section{A Fábrica Têxtil e a Fábrica do Conhecimento - significados e contextos.}

4 A agenda em proposição se vincula às atribuições inerentes ao ofício docente na FAETERJ Paracambi. É no reconhecimento da sua localização, arquitetura e funções, o ponto de partida para as pesquisas e estudos a serem desenvolvidos.

5 A FAETERJ Paracambi funciona nas instalações da Companhia Têxtil Brasil Industrial. Trata-se de um prédio de arquitetura inglesa, o que era predominante no conjunto das indústrias têxteis implantadas nos idos do século XIX e inícios do século XX, nos subúrbios da cidade do Rio de Janeiro e nas localidades situadas em fundo de vales ou próximas das serras que delimitavam os recôncavos da baía de Guanabara e baía de Sepetiba. $\mathrm{O}$ acesso e a proximidade ao recurso hídrico, assim como a possibilidade da circulação dos produtos por meio dos ramais ferroviários em implantação, eram determinantes. Tais indústrias foram indutoras da urbanização nesses lugares. As atividades da Companhia Têxtil Brasil Industrial se iniciaram em 1871 e prosseguiram até o ano de 1996 (SANTOS, 2017).

6 A FAETRJ Paracambi iniciou suas atividades "em abril de 2002, ocupando, a partir do segundo torreão, todo o lado direito do primeiro andar das instalações da antiga fábrica" (ibid. p. 83). o conjunto das dependências da fábrica, com destaque o seu prédio central, não comporta apenas as atividades da FAETERJ, mas também o Centro de Educação à Distância do Estado do Rio de Janeiro (CEDERJ), o Instituto Federal de Educação, Ciência e Tecnologia do Rio de Janeiro (IFRJ), a Escola de Música Villa-Lobos, além de projetos; comporta, também, em prédios anexos, a Secretaria de Meio Ambiente da cidade de Paracambi. Esse conjunto de instituições e atividades consagra o que se enuncia como Fábrica do Conhecimento, expressão cunhada em 2002 (ibid.).

7 Esta breve descrição indica conteúdos expressivos para o escopo desta comunicação. A localização das acomodações da FAETERJ Paracambi na fábrica sinaliza a compreensão sobre as correspondências simbólicas e históricas nesse prédio. Da fábrica têxtil (a industrialização e a urbanização que a pressupõem) à Fábrica do Conhecimento: 
remete-se aos vínculos com a história da técnica que se faz presente no território; remete-se ao trabalho em suas transformações no tempo e como imprimem sentido à formação para o trabalho.

8 Ao se qualificar a FAETERJ Paracambi como lugar referência para a realização de pesquisas e análises, delineia-se o contexto regional-metropolitano a ser objeto de investigação. Uma breve descrição desse contexto se faz necessária. Situa-se a FAETERJ Paracambi no que Leandro Dias de Oliveira e André Santos da Rocha (2014) definem como Oeste Metropolitano Fluminense, correspondente "ao segmento da região metropolitana do estado do Rio de Janeiro localizado na parte ocidental da Baía de Guanabara"; definição que também corresponde ao exposto por Leandro Dias de Oliveira e Floriano José Godinho de Oliveira (2018). O Oeste Metropolitano, para esses autores, comporta a distinção entre a Baixada Fluminense histórica, por assim dizer, e o Extremo Oeste Metropolitano - correspondente aos municípios de Queimados, Japeri, Paracambi, Itaguaí de Seropédica (mapa 1). Tanto a Baixada Fluminense histórica e o Extremo Oeste Metropolitano configuram-se como "dois polos de desenvolvimento produtivo", que qualificam o Oeste Metropolitano Fluminense (OLIVEIRA; ROCHA, 2014, p. 7-8).

Mapa 1: Baixada Fluminense (Oeste Metropolitano Fluminense) e Extremo Oeste Metropolitano.

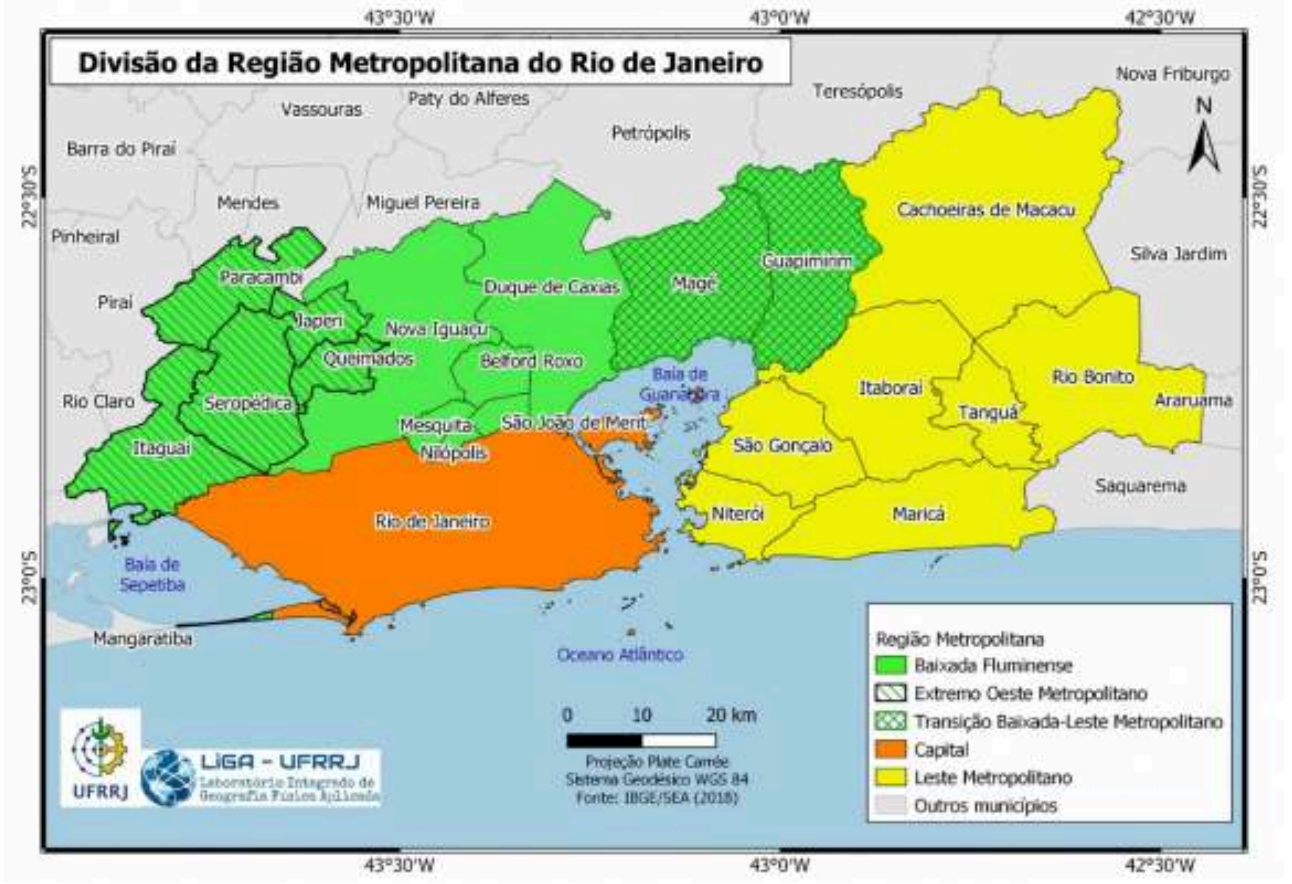

Fonte: OLIVEIRA e OLIVEIRA, L. (2018).

9 Há outra regionalização que se apresenta relevante para identificação da "área de influência" da FAETERJ Paracambi, que se refere aos municípios que compõem o Oeste Metropolitano Fluminense, cujos territórios, ou frações territoriais, estão inseridos na delimitação da Região Hidrográfica do Guandu (mapa 2). Essa delimitação muito se aproxima da delimitação do Extremo Oeste Metropolitano, mas informa algo significativo nesse reconhecimento regional, já que a delimitação da Região Hidrográfica do Guandu extrapola a delimitação formal da Região Metropolitana do Rio de Janeiro, em sua fração oeste e, por extrapolar, agrega o caráter regional-metropolitano que lhe é 
impresso. Sinaliza, assim, as problemáticas socioambientais referentes à questão hídrica em sua correspondência com as políticas de desenvolvimento no âmbito do urbano/regional, numa abrangência em que se integram a bacia de Ribeirão das Lajes, Rio Piraí e Rio Paraíba do Sul, por via de transposições, captações e represamentos hídricos voltados à produção de energia elétrica - obras que remontam à primeira metade do século XX (OLIVEIRA, 2013).

Mapa 2. Região Hidrográfica do Guandu.

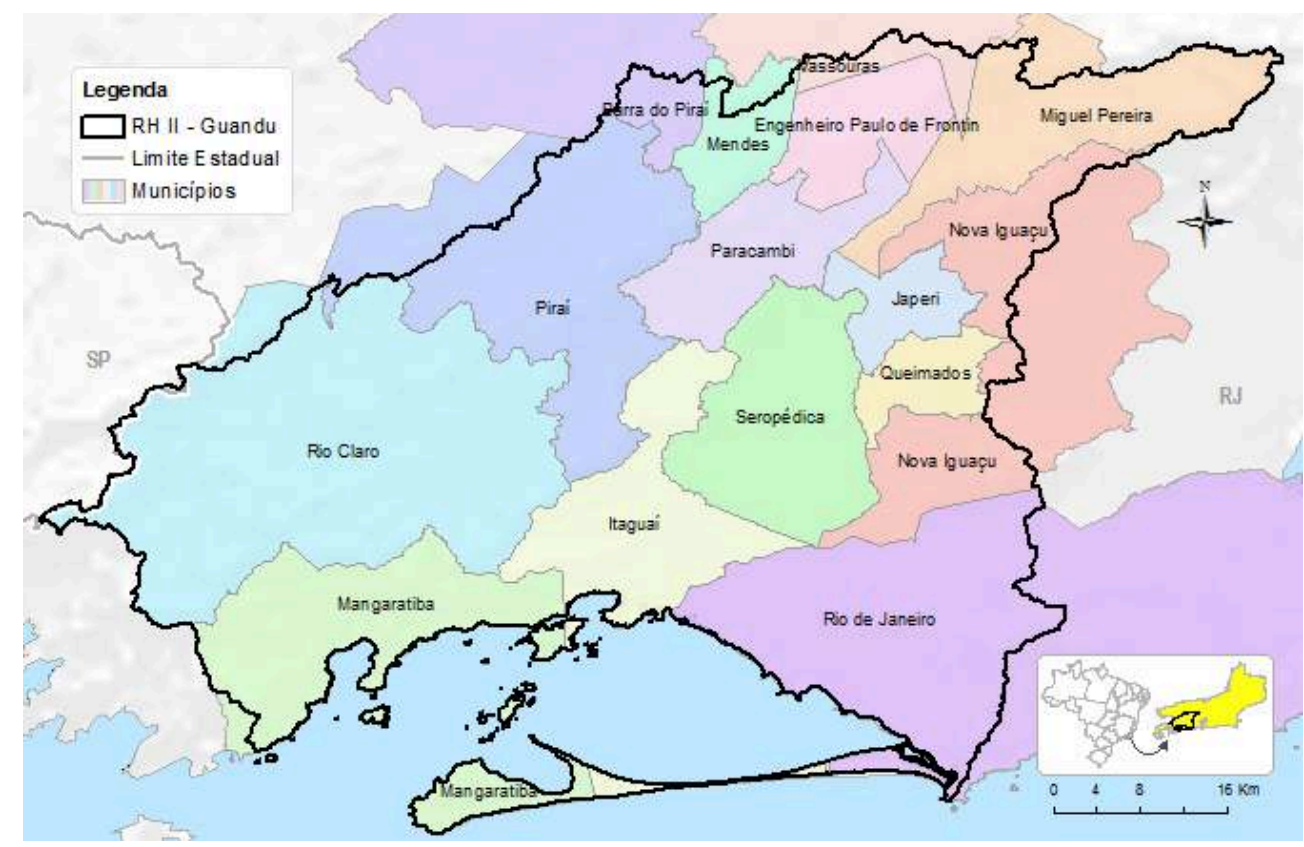

Fonte: http://www.sigaguandu.org.br/observatorioComite

O que se quer destacar refere-se à identificação na delimitação da Bacia Hidrográfica do Guandu no que se expressa na articulação do Oeste Metropolitano, mais destacadamente o Extremo Oeste Metropolitano, com a Região do Médio Vale Paraíba Fluminense e a Região Centro-Sul Fluminense. Agrega-se, aqui, a perspectiva de compreensão que destaque às formas de "integração territorial" no âmbito dessa articulação regional no que tange às redes técnicas de produção, circulação, logística, assim como projetos estratégicos, empreendimentos industriais e polos tecnológicos (OLIVEIRA; OLIVEIRA, 2018), o que resulta nos respectivos impactos e comprometimentos sociais, econômicos e socioambientais que tais empreendimentos e projetos imprimem no território. Refere-se, assim, às configurações do metropolitano em âmbito urbano-regional, o que se situa no que Sandra Lencioni (2017) define como Megarregião São Paulo-Rio de Janeiro.

O reconhecimento da Região Hidrográfica do Guandu, do Oeste Metropolitano Fluminense e Extremo Oeste Metropolitano como referências à delimitação regional em que a FAETERJ Paracambi está contida, assim como o que tal delimitação comporta de conteúdo histórico, atribui qualidade analítica à agenda em construção. É o ponto de partida que sinaliza o percurso da abordagem, em que esclarecimentos referentes aos conceitos de rede técnica e território se fazem necessários, já que delineiam as perceptivas metodológicas que embasam essa agenda. 


\section{Território e redes técnicas: perspectivas teórico-metodológicas}

12 Ao se buscar compreender os nexos entre a formação tecnológica e o desenvolvimento, faz-se imprescindível considerar as dinâmicas econômicas e sociais, assim como as intervenções políticas e sociais no território. Há de se observar a acepção do território como categoria analítica que comporta tal amplitude: o "território visto fundamentalmente como produto da apropriação do imaginário e/ou da identidade social sobre o espaço" (HAESBAERT, 2004, p. 39); pode ser compreendido, e traduzido, a partir das "relações de comunicações", vinculado a "uma ordem de subjetivação individual e coletiva", por meio da "relação intrínseca com a subjetividade que o delimita" (GUATARI, 1985, p. 110); constrói-se mediante o "espaço representado", segundo Raffestin (1993, p. 147), é "a imagem do espaço", ou seja, "o espaço que se tornou o território de um ator, desde que tomado numa relação social de comunicação".

13 No trato relativo a essa comunicação, destaca-se a compreensão de Milton Santos (2005) sobre o território usado, entendido como "sinônimo de espaço humano, espaço habitado" que, por sua vez, expressa-se por meio dos "objetos e ações"; dos "objetos técnicos" que nos possibilitam a "fluidez virtual" - prioritariamente "posta a serviço da competitividade" - e "das ações humanas, que são cada vez mais ações informadas, ações normatizadas" (p. 255-256). O entendimento é que o território usado, de acordo com Milton Santos, contempla o sentido de concretude que se configura a partir da materialidade e fluxos que correspondem à produção e reprodução do espaço. Pauta-se a dimensão econômica do território: o recurso, a produção e a realização do valor, a circulação e a logística, as condições de reprodução, o habitat e suas segregações, a mobilidade e suas temporalidades, os equipamentos, os usos.

14 Há de se notar que a acepção atribuída ao território usado conduz na compreensão da economia para além da separação entre o "econômico" e o "político". Refere-se a Wood (2011, p. 28), ao observar a perspectiva em Marx no tocante à correspondência entre os fatores econômicos e políticos no capitalismo, em que a distinção em "sua análise da economia política clássica é que ela não cria descontinuidades nítidas entre as esferas econômica e política"; sendo, assim, "capaz de identificar as continuidades porque trata a própria economia não como uma rede de forças incorpóreas, mas, assim como a esfera política, como um conjunto de relações sociais" (ibid.). o território usado comporta, dessa forma, o sentido político da produção, realização e extração do valor, assim como da produção e reprodução do social, sentido político que se expressa por via das estratégias, discursos, representações, sujeitos.

É possível observar que a amplitude atribuída ao conceito de território conduz à compreensão sobre a sua correspondência analítica com os conceitos de rede e rede técnica. Claude Raffestin (1993) informa sobre a amplitude da rede no que se refere à correspondência entre poder-circulação-comunicação. Conforme observa, circulação "e comunicação procedem de estratégias e estão a serviço delas" (p. 204). Tais redes (de circulação e comunicação) "contribuem para modelar o quadro espaço-temporal que é todo território. Essas redes são inseparáveis dos modos de produção dos quais asseguram a mobilidade" (ibid.). São, também, "sistemas sêmicos materiais" e, como tais, "surgem de uma 'leitura' ideológica em vários níveis: enquanto são traçadas, enquanto são construídas e enquanto são utilizadas ou, se preferirmos, "consumidas"' (ibid.). Dessa forma, desenho, "construção e utilização de uma rede dependem dos 
meios à disposição (energia e informação), dos códigos técnicos, sociopolíticos e socioeconômicos, assim como dos objetivos dos atores" (ibid.). Nessa perspectiva, a rede comporta a técnica, a informação e a política.

16 A rede expressa, também, tal amplitude, pelo fato de ser "global e local, uma e múltipla, estável e dinâmica"; comporta, "assim, a instantaneidade e a simultaneidade" (DIAS, 2005, p. 23; SANTOS, 1977, p. 222). As redes são, remetendo ainda a Milton Santos (ibid. p. 221), técnicas e sociais, materiais e viventes; são mediações, "mas também momentos da produção, produtoras de um novo espaço" (LENCIONI, 2017, p. 171); as redes “jamais são completamente desmaterializadas", de uma forma ou de outra, estão sempre "desenhando materialmente territórios" (HAESBAERT, 2004, p. 301). Observam-se, também, as redes por via das configurações constituídas e pautadas pelas ações, movimentos e ativismos sociais, no caso, as redes sociais movimentalistas (DOIMO, 1995).

A rede, no que se refere à sua amplitude, reporta ao entendimento do conceito de redes técnicas. Trata-se da compreensão de que o "conceito de redes técnicas está amplamente referido ao momento da circulação no sistema produtivo e social, implicando não só a circulação de mercadorias, mas também de pessoas, informações, fluxos financeiros e dados" (OLIVEIRA, 2020, p. 216-217). Porém, "essas redes são também modificadas, com a inclusão de inovações que produzem novas perspectivas tecnológicas"; como exemplo, as "redes imateriais de comunicação, que permitiram a transferência de dados por meio de computadores apoiados em sistemas de transmissão e recepção cujas bases físicas têm pouca ou nenhuma visibilidade" (ibid.). o que se quer destacar refere-se aos nexos alusivos às expressões econômicas e políticas presentes na rede técnica, em tempos em que a circulação e a comunicação são cada vez mais pautadas pelo informacional, que potencializam as formas de produção e extração do valor, assim como as formas de controle e regulação.

Faz-se importante retornar ao que já foi indicado nessa comunicação no que se refere a uma perspectiva de compreensão da constituição das redes técnicas em seus nexos históricos que delineiam uma geografia da técnica, por assim dizer: há uma história da técnica que é constitutiva dos territórios, das redes, do ambiente; nos lugares, nas regiões. Márcio Rufino (2019) apresenta a correspondência entre geografia e engenheira "nas primevas concepções de redes, em um estudo das redes ferroviárias promovidas pelo engenheiro ferroviário francês Leon Lalanne, na década de 1860" (p. 273). Rufino refere-se à Leila Christina Dias (1994) ${ }^{1}$, informando que, segundo a autora, o pioneirismo "do debate a propósito das redes está atrelado, igualmente, a um ideário no qual a 'integração regional' ou a 'integração de mercados regionais', a 'quebra de barreiras fiscais' e demais 'obstáculos à circulação de mercadorias, matérias-primas' e capitais aparecem em estudos diversos ao longo do século 20" (RUFINO, ibid.).

19 Atribuir qualidade analítica aos nexos históricos constituintes das redes técnicas e dos territórios embasa e sinaliza ao conjunto dos estudos e pesquisas que se pretende neste plano de trabalho. Trata-se em operar com procedimentos que nos aproximam das noções de verticalidades, horizontalidades, assim como as densidades (densidade técnica, densidade informacional, densidade comunicacional), conforme Milton Santos (1997) ${ }^{2}$. Agrega-se, também, numa perspectiva de amplitude do método, as complexidades verticais e complexidades horizontais em Lefebvre (1975) em sua correspondência com os momentos e procedimentos no âmbito do método regressivo-progressivo, assim como as interpretações de Martins (1996), em que este entende que essa "dupla complexidade se desdobra em procedimentos metodológicos que identificam e recuperam 
temporalidades desencontradas e coexistentes" (p. 21). Tais noções e categorias permitem apreender o real em sua complexidade, o que possibilita a compreensão sobre os impactos e desdobramentos da política e da economia no território. A perspectiva analítica que se delineia tem como premissa o reconhecimento das verticalidades que lhe atribui conteúdo e sentidos. Por sua vez, é nas escalas da cidade (em seus fragmentos) e do urbano em suas expressões regionais que é possível identificar a concretude das políticas e processos sociais: observam-se, nessas escalas, as densidades, assim como as redes - em seu caráter mediador com os processos e expressões no âmbito global.

Identificar os nexos entre as redes técnicas em sua configuração no território conduz ao debate concernente à modernização e ao desenvolvimento; debate que se expressa no âmbito da política, da ação do Estado; debate que expressa o modelo de desenvolvimento que se imprime e os rebatimentos regionais e locais em seus comprometimentos sociais, econômicos e socioambientais. Tais debates, muito mais que referencias pontuais ao trato relativo à formação tecnológica, informam premissas que fundamentam as políticas relativas à expansão e à consolidação da rede de escolas, institutos e faculdades de formação tecnológica, assim como das políticas em torno da inovação e desenvolvimento.

\section{A formação tecnológica (e o tecnólogo) em questão}

21 A formação para o trabalho assume sua relevância por compor, em seus princípios, o sentido ético-valorativo que pressupõe o domínio das técnicas, procedimentos, protocolos e normas que se fazem presentes nas práticas e ações inerentes ao mundo do trabalho. Engendra, dessa forma, os princípios e práticas correspondentes à produção e reprodução do valor, e o que destes comportam como transbordamentos para o social e o político.

Princípios, por sua vez, pautados pelo predomínio de uma "concepção de formação humana" limitada "ao desempenho em determinados conteúdos estabelecidos (estreitamento curricular) medidos por meio de testes padronizados" (BERTAGNA; OLIVEIRA; MIRANDA, 2015, p. 70). O que contrapõe a perspectiva de formação humana integral, que corresponde, conforme Manacorda, à "totalidade" das "capacidades produtivas e, ao mesmo tempo, a uma totalidade de capacidades de consumo e prazeres"; deve-se, então, "considerar o gozo daqueles bens espirituais, além dos materiais, e dos quais o trabalhador tem estado excluído em consequência da divisão do trabalho" (2010, p. 96, apud id. p. 74$)^{3}$. Por sua vez, a concepção de formação humana que embasa o estreitamento curricular pode ser apreendida por via das expressões discursivas presentes nas proposições referentes às políticas educacionais no interregno entre os anos 1980, quando ocorreram a "expansão do ensino médio técnico" e a "fragmentação da educação profissional nos anos 1990" (FRIGOTTO; CIAVATTA, 2006, p. 11). Observa-se, nos anos 1990, o quase total desaparecimento de expressões como "educação integral, omnilateral, laica, unitária, politécnica ou tecnológica e emancipadora", em contraponto, realça-se "o ideário da polivalência, da qualidade total, das competências, do cidadão produtivo e da empregabilidade" (id. p. 56).

23 Atenta-se ao fato de que a diretrizes presentes nas políticas relacionadas à juventude por meio das agências e órgãos governamentais vinculam-se a determinadas ações e 
políticas implantadas em escala global. Ações essas que se constituem mediante o que Furiati (2010, p. 12) define como "comunidades epistêmicas internacionais"; destaca-se, assim, o papel da "Organização das Nações Unidas (ONU)", do "Banco Mundial (BM) e a Organização das Nações Unidas para Educação e Cultura (UNESCO)". O jovem é enunciado como protagonista do desenvolvimento, conforme ressalta o documento "Vozes Jovens" (BANCO MUNDIAL, 2004) que "enaltece a autonomia e auto-organização dos jovens" (FURIATI, 2010, p. 41). Furiati chama atenção para a "leitura dos documentos de política educacional do Banco Mundial, da UNESCO e da CEPAL, elaborado na última década atesta o fato", em que existe "uma íntima relação entre o liberalismo e os temas de auto-organização e autonomia." (ibid.).

Neise Deluiz (2010), por seu turno, informa que o documento produzido pelo Banco Mundial (intitulado "Relatório sobre o desenvolvimento mundial de 2007 - o desenvolvimento e a próxima geração") reitera "a perspectiva liberal assumida desde os anos 1980", em que "a atuação dos governos deveria garantir o ideário do livre comércio e da flexibilização do mercado de trabalho". Aceita, "como consequência, o trabalho precário, informal ou autônomo, medidas necessárias à ampliação de oportunidades para os jovens". O jovem passa, assim, a ser considerado "capital humano relevante para a superação das condições de pobreza", em que "sua participação cívica produtiva é condição fundamental para a garantia da governabilidade" (Ibid. p. 22).

Faz-se importante observar que as referências a essas últimas autoras remetem à temática concernente à juventude e à formação tecnológica, o que demanda esclarecimentos e será apontado à frente. $O$ registro se faz necessário por levar a indagar de que maneira tais princípios que embasam as políticas em torno da juventude forjam a formação do tecnólogo? Cursos cujo processo de regulação e definição de seus escopos se dá a partir de 1969, com a promulgação do Decreto $\mathrm{n}^{\circ}$ 547, "que dispôs sobre a autorização das Escolas Técnicas Federais para realizar a oferta de cursos profissionais superiores de curta duração" (MACHADO, 2008, p.3); cursos que visavam "formar para o trabalho de operação e gestão" (Ibid. p. 4). 0 tecnólogo configura-se, assim, "como uma categoria de trabalhador qualificado" que "expressa à dinâmica de surgimento de novas profissões e especialidades"; situa-se "no polo dinâmico do setor produtivo, entretanto, está sujeito a certa 'taylorização' representada pela formação de duração mais curta e pelo grau circunscrito de autonomia" (ibid., p. 15).

Por sua vez, é possível observar que os componentes da pesquisa e da extensão passam a pautar tais políticas e práticas, já que se faziam presentes na "Declaração da Conferência Mundial sobre Ciência e o Uso do Conhecimento Cientifico", em 1999, em que a "ciência para o século XXI" deve ter, como umas das suas aspirações, a "renovação do ensino da ciência e da tecnologia", tendo como um dos objetivos "a promoção da compreensão pública da ciência e da tecnologia como parte da cultura" (MACHADO, ibid., p. 21-22). Identificam-se, assim, avanços, como a criação do "Programa Institucional de Bolsas de Iniciação em Desenvolvimento Tecnológico e Inovação (PIBITI) pelo CNPQ" em junho de 2006 (ibid., p. 24). O que parece desembocar, como movimento e conjuntura, na "criação dos Institutos Federias de Educação, Ciência e Tecnologia, em 2008" (SOUZA, 2019, p. 2), e como a implantação desses potencializa políticas e práticas voltadas ao desenvolvimento local, regional (ibid., p. 6). Configurase, assim, como um período profícuo, mas que cuja realização dessas aspirações se constitui pela incompletude e descontinuidades. 
estudante em questão ou já é um trabalhador em busca de nova (e melhor) qualificação, ou é um trabalhador em potência. $O$ escopo da sua formação vincula-se às demandas das áreas de serviços, gestão e controle; no planejamento das políticas e ações públicas; na produção de âmbito tecnológico e no âmbito da comunicação e da imagem. Por sua vez, há de se destacar que se refere ao trabalho em sua nova morfologia, em que, segundo Antunes (2018, p. 77): no "topo da pirâmide social" encontram-se "os trabalhos ultraqualificados que atuam no âmbito do informacional e cognitivo" (como por "exemplo os trabalhadores das indústrias de software e das TICs"); na "base ampliam-se a informalidade, a precarização e o desemprego"; no meio, "encontramos a hibridez", ou seja, "o trabalho qualificado que pode desaparecer ou erodir" devido às "alterações temporais e espaciais que atingem as plantas produtivas ou de serviços em todas as partes do mundo". Há de se observar que, apesar do aperfeiçoamento dos marcos que definem a qualificação do tecnólogo, ainda se fazem presentes nas referências aos cursos de formação em tecnólogo os "estigmas preconceituosos que demarcam a história da educação profissional brasileira e os fazem serem vistos como cursos de segunda classe, com baixo prestígio" (MACHADO, ibid., p. 13).

Refere-se, assim, ao estudante, em sua condição e ao que ele experimenta como possibilidade no âmbito do mundo do trabalho: que perspectivas diante do mundo e da sua existência são forjadas e como a formação para a tecnologia e a inovação cumpre o papel em potencializar essas perspectivas?

O que se pretende contemplar aqui é que analisar as perspectivas desses estudantes diante do trabalho e da formação tecnológica conduz apreender esse trabalho e as políticas que o constituem, assim como as dinâmicas de reprodução em que esses estudantes, adultos e jovens, estão inseridos; conduz, também e por fim, o reconhecimento da capacidade de apropriação de sua condição - o possível. A questão, a saber, é como a formação do tecnólogo potencializa essa capacidade?

\section{Sobre inovação e desenvolvimento}

O exposto até o momento conduz a necessidade de se pensar a correspondência inovação e desenvolvimento. $O$ que se expõe refere-se a abordagens prévias, porém basilares para as análises em construção.

31 No que se refere à inovação, é possível afirmar que o construto conceitual sobre a inovação referencia-se como ponto de partida, de acordo com Thales de Andrade (2004), as formulações em Joseph Schumpeter ([1911]1982)4, "no início do século XX", em que esse entende que o "comportamento empreendedor, com a introdução e ampliação de inovações tecnológicas e organizacionais nas empresas, constitui um fator essencial para as transformações na esfera econômica e seu desenvolvimento no longo prazo" (ANDRADE, ibid. p. 91). Observa que, na "esteira das elaborações de Schumpeter, há algumas décadas o termo inovação foi cunhado no âmbito da OCDE com vistas a promover uma interação mais efetiva entre o setor produtivo e as áreas de pesquisa e conhecimento"; mais precisamente a partir dos anos 1980, com a "globalização da economia e a flexibilização dos formatos organizacionais envolvendo empresas, agências estatais e centros de pesquisa, a formação e desenvolvimento de redes passa a ser um tema central dos pesquisadores sobre inovação" (ibid. ).

Espaço e Economia, 22 | 2021 

processo inovativo, que para ele deve se construir a partir da ação estratégica dos inovadores" (ANDRADE, ibid. p. 92). Na ação estratégica, "o inovador precisa ao mesmo tempo controlar o contexto social em que se desenrola a prática inovadora e se adaptar a ele"; a "manipulação constante do contexto em que se desenrolam as controvérsias garante a satisfação das várias condições em jogo para a resolução de conflitos e consolidação das inovações" (ibid.). Por fim, observa que, enquanto "a tradição schumpeteriana compreende a dinâmica inovativa, consagrando as "possibilidades produtivas e corporativas, a perspectiva de Latour e da sociologia construtivista aposta na discussão circunstancial e coletiva da prática da inovação, envolvendo agentes econômicos e não econômicos (ANDRADE, ibid. p. 93). inovação, conforme exposto, são perpassados pelas transformações decorrentes da inovação tecnológica e organizacional no âmbito do trabalho e que cujos desdobramentos na dimensão das "práticas sociais" se dão. 0 que se coloca em questão é a racionalidade que se imprime nessas inovações. Faz-se necessário observar a correspondência entre inovação e as "idades da máquina", no que essas se constituem como "saltos tecnológicos" e o que impõem como racionalidades (ALVES, 2011). No que se refere ao trato nessa comunicação, destacam-se as transformações que se constituem na configuração histórica do fordismo, a partir dos anos 1920, até o que se define como toyotismo, em tempos presentes de acumulação flexível (ibid.). A ideia chave, aqui, é que o debate em torno da inovação se pauta na perspectiva da constituição da hegemonia social em que tais modos de regulações e reestruturação produtiva se impõem. Em tempos presentes, é possível, assim, contextualizar a discussão circunstancial e coletiva da prática da inovação, num campo em que se agudiza "a contradição entre racionalidade intraempresa e a irracionalidade social", em que o "espaço-tempo da produção do capital se contrasta com o espaço-tempo esgarçado da reprodução social" (ibid. p. 102-103). o que se quer colocar em tela é destacar o campo de contradições em que a temática da inovação é posta no presente. A abordagem referente à inovação deve explicitar, assim, o seu caráter político, ao explicitar tais contradições.

Nesse sentido, a perspectiva de compreensão sobre as temáticas concernente à inovação deve levar em conta o reconhecimento nas transformações no mundo do trabalho e no que essas resvalam, e correspondem, à esfera da dimensão cotidiana, da realização da vida. Floriano de Oliveira $(2021$, p. 213) observa (em sua referência à tríade "meios de produção - relações de produção - relações sociais", em Marx) não ser possível, metodologicamente, "uma leitura restrita à dimensão econômica da incorporação da modernização dos meios de produção, como se fora apenas uma incorporação de novas tecnologias na organização das forças produtivas"; "implicações nas esferas sociais, políticas, culturais são sempre referências concretas" influem "em todas as relações da sociedade". A inovação é "socialmente produzida e incorporada nas práticas sociais" (ibid., p. 215).

Faz-se necessário destacar a correspondência entre inovação e território como processo de produção e extração do valor, conforme observa Roberto Pessanha (2021) e Mario Vale (2021), no que ambos definem como capitalismo de plataforma e, segundo Mario Vale, corresponderia à noção de "cidade inteligente", no que comporta como significado a partir da "poderosa narrativa da tecnologia e o do empreendedorismo" 
(p. 31). Apesar da "cidade inteligente" se constituir como uma "estrutura política alinhada com os interesses de poderosos atores públicos e privados" (ibid., p.33), é possível conceber uma "cidade inteligente" menos desigual, "que necessita de políticas orientadas por um modelo de inovação que incorpore uma forte dimensão social e envolvimento da comunidade" (ibid.). Trata-se de uma entrada analítica importante para o escopo dessa agenda, o que coloca em pauta o debate político em torno da inovação. Na identificação das estratégias e políticas em torno da inovação, o território em questão é o território usado, o que sinaliza ao debate concernente ao modelo de desenvolvimento que embasa tais estratégias e políticas.

Nessa comunicação, o trato relativo à inovação e ao desenvolvimento exige maiores fundamentações, o que solicita investiduras futuras. No que se refere ao desenvolvimento, situa-se especificamente a abordagem escalar como problematização no que tange ao desenvolvimento local/regional. Vai-se ao encontro com as formulações de Brandão (2012), ao que define como localismo. Observa-se o traço neoliberal presente nas narrativas em torno do poder local em que se identifica ser "a teoria do poder local" umas "das armas usadas" na perspectiva das políticas, ações e práticas de cunho neoliberal. Criam-se, assim, "falsas ideias do desenvolvimento local, da cidade (ou da região) competitiva, emanadas de ações locais ou regionais". Destaca-se o entendimento de que seus "seguidores" parecem não perceber "que o propalado poder local não conta com as prerrogativas necessárias à formulação e execução de uma política de desenvolvimento que são os instrumentos básicos da política econômica - o comando sobre a taxa de juros, de câmbio, do crédito e da fiscalidade necessária" (p. 25, itálicos do autor).

37 Adiante, o autor sinaliza a sua perspectiva metodológica a partir "da discussão de propostas alternativas" de desenvolvimento "e pelo tratamento adequado da articulação de todas as escalas geográficas" (ibid., p. 36). Observa, assim, que é "preciso discutir a espacialidade dos problemas e implementar políticas levando em consideração a escala específica desses problemas, mas em um contexto em que esteja presente um projeto nacional de desenvolvimento" (ibid.). Observa, também, a relevância das "escalas intermediárias" que, para seu entendimento, "ganham novo sentido e importância nessa fase do capitalismo" (ibid.).

Há de se notar que não se trata de negligenciar a escala do lugar, mas sim reconhecer os nexos entre o lugar, a dimensão regional e as verticalidades em que esse é forjado, o que conduz ao reconhecimento das várias escalas de abordagem em suas conexões, redes, densidades que expressam o modelo de desenvolvimento em questão. Há de se lembrar as formulações abordadas por Bernardo Mançano Fernandes (1999) sobre o que define como os "processos de espacialização e territorialização da luta pela terra" (p. 17): referenciado em suas formulações, é possível identificar a referência ao lugar (o lugar como presença construída na luta pela terra) como escala de resistência e de experimentações de práticas e econômicas solidárias. Há limites e impossibilidades no que se refere ao enfrentamento das políticas e estratégias vinculadas aos projetos hegemônicos - estes expressos no que Dardot e Laval definem como "governabilidade neoliberal" (2017, p. 143) ${ }^{6}$. Expressa as verticalidades, conforme exposto por Milton Santos, como citado (1997), mas é possível experimentar horizontalidades e configurações reticulares (redes de diálogos, intercâmbios e ações sociais) que pautariam resistências e concepções de desenvolvimento de caráter anticapitalista, socializante: experimentaria, assim, uma territorialidade da luta pelo comum, pelo 
direito ao uso, em que a temática sobre o desenvolvimento seria um ponto de pauta necessário.

\section{Percursos e aproximações.}

O exposto até então sinaliza o delineamento do plano de pesquisas, estudos e interlocuções em torno do que foi denominado como uma geografia sobre a rede de formação tecnológica diante da configuração do mundo do trabalho, da inovação e do desenvolvimento em seus processos e expressões no território. $O$ enunciado informa, de certa maneira, determinados eixos analíticos que organizam e delineiam respectivo plano de trabalho: o desenvolvimento em sua expressão urbano-regional; a formação tecnológica e seu papel como vetor do desenvolvimento e inovação; o aluno em suas determinações e motivações. Trata-se do que será abordado a partir daqui.

Porém, há o que antecede como reconhecimento histórico que embasa a geografia que se quer delinear. Refere-se aos significados presentes na implantação da fábrica de tecidos, ou, para ser mais exato, nas fábricas de tecido (Brasil Industrial - 1871; Tecelagem Santa Luísa - 1887), no que corresponde à constituição da Cidade de Paracambi. O que não se restringe às fábricas, mas também mediante a chegada da ferrovia em 1861, ligando a Estação Macacos, hoje Paracambi, à Estação Belém, hoje Japeri; possibilitando, "juntamente, com a abundância de rios e quedas d'agua, a implantação" das "indústrias têxteis em Paracambi" (SANTOS, 2017, p. 20). O que remete ao exposto pelo professor André dos Santos da Rocha, em diálogo com o Professor Floriano José Godinho de Oliveira e o autor dessa comunicação, ao observar, referenciando as formulações em Duby (1984), o papel predominante, em alguns casos, da rede técnica na configuração das cidades. Trata-se de vigorosa pista investigativa que sinaliza à compreensão sobre a constituição da rede técnica, no que essas comportam de conteúdo histórico, como estruturantes na configuração do território: a fábrica e a ferrovia como expressões de uma modernidade que se anunciava; a questão habitacional e a vila operária; o tecido urbano que se forjava; os domínios sobre os recursos naturais transformados em valor e em aporte tecnológico - o recurso hídrico como questão e a demanda pela produção de energia hidrelétrica, como já exposto (OLIVEIRA, 2013). No trato relativo a essa agenda, descrever e analisar processos e dinâmicas referentes a tal reconhecimento é a empreitada em andamento, que se pretende retorno breve.

41 O reconhecimento histórico da configuração das redes técnicas e do território embasa e fornece uma perspectiva de estudos e pesquisas referentes às políticas, às estratégias $\mathrm{e}$ aos projetos em torno do desenvolvimento em âmbito urbano-regional no presente. Refere-se, assim, o eixo analítico concernente ao que se pode definir como densidades e redes da inovação e do desenvolvimento. O leque de objetos de estudos, pesquisas e debates, é amplo, o que indica a necessidade de se conceberem projetos coletivos de pesquisas em torno da produção de diagnósticos referentes às redes técnicas e do conhecimento diante dos processos de modernização e desenvolvimento em curso. Busca-se apreender, também, as derivações no que tange ao mundo do trabalho, assim como os comprometimentos sociais, econômicos e socioambientais provenientes dessas políticas e modernizações.

Tal perspectiva sinaliza, por sua vez, o reconhecimento do que de fato é potencializado pela implantação dessa rede de formação tecnológica no que tange ao desenvolvimento 
e suas expressões no território. Deriva-se, assim, o eixo analítico cujo conjunto de questões postas pauta-se pelo lugar estratégico, no campo da pesquisa e da inovação, que se é atribuído aos cursos de ensino médio integrado à formação técnica nas escolas técnicas e nos cursos tecnológicos de formação universitária em faculdades e institutos. Que termos cumprem de fato esse papel? Como se relacionam com os processos de modernização e desenvolvimento em âmbito local e urbano-regional? Destaca-se a possibilidade de estudos concernentes às práticas e vivências na formação acadêmica por via de projetos de pesquisa, extensão e transferências de tecnologias que propiciem estratégias vinculadas a economias e práticas locais e em rede que potencialize o desenvolvimento de forma sustentável e justa: a inovação diante das possibilidades mitigadoras do modelo desigual de desenvolvimento; a inovação para além das tecnologias da informação e da comunicação e que coloca em pauta saberes e práticas outros.

Uma outra entrada está na identificação de como a inserção desses alunos nos debates acadêmicos, nos projetos de pesquisa e extensão, nos estágios e monitoria, potencializa posicionamentos e práticas em relação à sua condição e possibilidades diante do mundo? Nesse eixo analítico, o aluno é posto em tela. 0 que se busca são entendimentos prévios referentes às condições de existência e reprodução social vivenciada por parte desses alunos: experimentação que se vivencia diante das transformações no mundo do trabalho, nas materialidades, formas de produção e realização do valor e que impõe um modo de realização da vida; experimentação que se desdobra nos usos e apropriações possíveis, o que sinaliza a construção de posicionamentos diante da sua condição e do mundo.

No correr da elaboração dessa agenda, eventos e diálogos conduziram à aproximação com objeto de análise que se observou expressar nexos significativos com o campo temático em tela. Refere-se à possibilidade de estudos com o intuito de identificar e caracterizar as proposições em torno dos usos e configurações dos ramais ferroviários presentes no Extremo Oeste Metropolitano Fluminense e seu entorno. O que se enseja, a partir de projetos de pesquisa, no que se tem denominado como Para Além Japeri: referência à última estação do ramal ferroviário de passageiros, cuja denominação é homônima a essa estação; e dessa, ramal complementar ligando à Cidade de Paracambi. O ponto de partida diz respeito ao reconhecimento (histórico) da configuração da rede ferroviária em âmbito regional, identificando os nexos referentes aos processos de modernização e inovação impressos no território. O que sinaliza análises correspondentes à pauta, no presente, em torno da expansão e renovação de ramais ferroviários, destacadamente às dinâmicas de integração territorial no âmbito regionalurbano em que se insere o Extremo Oeste Metropolitano7.

Delineiam-se, também, estudos sobre as condições de mobilidade urbana sob o predomínio da modalidade de deslocamento trem-ônibus (e/ou van): a pesquisa aqui se refere a essas condições por parte dos alunos da FAETERJ Paracambi; indica as temporalidades em que se vivencia o cotidiano e as condições de reprodução social por parte desses alunos ${ }^{8}$. Há indicativos que permitem produzir um mapeamento preliminar a partir dos principais eixos viários de locomoção. Há de se observar que tais movimentos pendulares não se restringem aos limites formais da Região Metropolitana Fluminense, em sua fração oeste, o que, no caso específico da mobilidade dos alunos da FAETERJ Paracambi, é bastante expressivo. 


\section{Considerações (que não são necessariamente) finais}

durante elaboração de tese de doutoramento (LOPES, 2018), porém, com outras feições. Desloca-se do ativismo juvenil no que estes revelam como potencialidades e enquadramentos (pensando, assim, a emergência da temática juvenil em um contexto de capturas) para a compreensão sobre o estudante no âmbito da formação tecnológica, mais especificamente, nessa comunicação, o tecnólogo. o ponto de partida é, de fato, o estudante da FAETERJ Paracambi, onde, a partir de observações sobe esse, a amplitude do campo temático que delineia essa agenda se apresenta; amplitude que se faz presente, também, a partir do deslumbramento diante da monumentalidade da antiga fábrica - a verticalidade histórica se apresenta. Ao observar o estudante, resgatam-se interpretações desenvolvidas no processo de elaboração da tese, na perspectiva de pensar o enfoque geracional como possibilidade analítica referente às dinâmicas e inserções na formação tecnológica e, como derivação, as perspectivas que se constituem diante do futuro".

O geracional expressa possibilidades interpretativas sobre as condições de reprodução social e existência desses alunos: é uma categoria que permite apreender dimensões da particularidade em que esses, predominantemente jovens, mas não exclusivamente, experimentam, de forma distinta, o presente. O geracional, no trato que se pretende nessa agenda de estudos, sinalizaria a compreensão sobre as diferenças que revelam a condição social desses estudantes (contêm, além do etário, o gênero, a raça e, 
inevitavelmente, a classe), em que a temática referente à inserção ao mundo do trabalho articula-se com a temática da formação para o trabalho e com as suas condições de existência. Agrega-se, assim, a capacidade de mobilidade e acesso à cidade e aos bens coletivos como componentes que expressam a inserção (e condição) desses estudantes ao mundo do trabalho, como também na possibilidade de realização da vida.

Dessa forma, diante da formação tecnológica e do que comporta como possibilidades no âmbito da inovação e do desenvolvimento, o território entra em questão. 0 território, que ao comportar a dimensão econômica e política, a objetividade e a subjetividade, é também objeto da ação pedagógica. Conforme já exposto, o que se almeja é a possibilidade em se conceber o diálogo entre a formação tecnológica e a inovação no âmbito dos lugares e das redes, sociais e técnicas, que potencializam a experimentação da criação, da cooperação, do coletivo - respostas e resistências possíveis ao contexto de crise e precarização.

Tal perspectiva de entendimento reporta ao reconhecimento da natureza política em que os princípios e fundamentos que constituem a formação tecnológica se forjam, como já sinalizado. Porém, há de observar ser necessário maior detalhamento analítico referente às políticas e conjunturas em torno da criação e investimentos nesses cursos. Busca-se situar a expansão da rede de formação tecnológica em sua correspondência com a expansão da escola pública como expressão do processo de modernização da sociedade brasileira: há o que distinguir, já que a formação tecnológica, no ensino médio e no ensino superior, não comporta a universalidade que pressupõe o ensino básico regular e que cujo pressuposto da formação tecnológica é a especialização; mas há seus nexos e vínculos. Na perspectiva de compreensão desses nexos, aproxima-se ao que Eveline Algebailé (2009) define como robustecimento da escola, que se constitui na busca de respostas a expectativas em torno das "lutas pelo alargamento do direto à educação", porém, induziu, por via da "simulação ou realização "encurtada" destas expectativas, a sua "'ampliação para menos', que reitera desigualdades e reinventa destituições" (ibid. p. 329). No trato analítico sobre os institutos e faculdades tecnológicas, é possível reconhecer que nas "lutas pelo alargamento do direto à educação" as demandas correspondentes à expansão do ensino técnico se faziam presentes; como também é possível reconhecer a sua "realização "encurtada". Um mergulho nos dilemas relativos a gestões e dinâmicas acadêmicas nesses institutos e faculdades seria uma empreitada interessante que poderia ser desenvolvida por meio de interlocuções, debates e projetos coletivos.

O que se expôs corresponde a um cenário possível de estudos, investigações e diálogos. Ao ser possível, é aberto na perspectiva de que a dimensão do real surpreenda. 0 que, potencialmente, sinaliza a novas questões, cujo enfrentamento conduz a problematizar os nexos com os movimentos do mundo e do pensamento. Nesse exercício, a interlocução com os alunos é basilar - interlocutores e sujeitos da observação e da ação. 


\section{BIBLIOGRAFIA}

ALGEBAILE, E.B. Escola pública e pobreza no Brasil: a ampliação para menos. Rio de Janeiro: Lamparina - Faperj, 2009. ISBN: 978-85-98271-70-5.

ALVES, G.T. e subjetividade: o espírito do toyotismo na era do capitalismo manipulatório. São Paulo: Boitempo, 2011. 168 p.

ANDRADE, T. Inovação tecnologia e meio ambiente: a construção de novos enfoques. Ambiente \& Sociedade, VII, pp.89-105, 2004.

ANTUNES, R. L. C. O privilégio da servidão: o novo proletariado de serviços na era digital. 1. ed. São Paulo: Boitempo, 2018. 325 p.

ANTUNES, R. L. C. Os sentidos do trabalho: ensaio sobre a afirmação e negação do trabalho. 2. ed. São Paulo: Boitempo, 2009. ISBN 978-85-85934-43-9. 280 p.

BERTAGNA, R.H.; OLIVEIRA, S. B.; MIRANDA, A. C.. Por uma compreensão do conceito de formação humana para a construção da qualidade social da Educação. In : SALES, José Albio Moreira de..., et al. (Orgs.). A didática e a prática de ensino na relação com a sociedade. 1. ed. Fortaleza: EdUECE, 2015.

BRANDÃO, C. Território \& Desenvolvimento: as múltiplas escalas entre o local e o global. 2. ed. Campinas: Editora UNICAMP, 2012. 229 p.

CARDOSO, A. Introdução: Juventudes, gerações e a atualidade de um tema clássico. In: (organizador). Juventudes e desigualdades. Rio de Janeiro: Azougue Editorial, 2014. p. 5-45.

DARDOT, P.; LAVAL, C. Comum: ensaio sobre a revolução no século XXI. São Paulo: Boitempo, 2017. ISBN: 978-85-75595-81-7. $647 \mathrm{p}$.

DELUIZ, N. Projovem trabalhador: avanço ou continuidade nas políticas de qualificação profissional? Boletim Técnico do SENAC, XXXVI, n. 2, pp. 19-31, 2010, <https://www.bts.senac.br/ bts/article/view/232/215>. Acesso em: 16 de janeiro de 2012.

DIAS, L.C. D. Geografia e qualidade de vida: pensando as redes técnicas. Geosul, IX, pp. 7-15, 1994.

DIAS, L.C. D. Os sentidos da rede: notas para discussão. In : DIAS, L. C.D.; SILVEIRA, L. L. (Orgs.). Redes, sociedades e territórios. 1. ed. Santa Cruz do Sul: EDUNISC, 2005.

DOIMO, A.M. A vez e a voz do popular: movimentos sociais e participação política no Brasil pós-70. Rio de Janeiro: 1995. 352 p. ISBN: 85-7316-038-1.

DUPUY, G. Villes, systèmes et réseaux. Le rôle historique des techniques urbaines. In : Les réseaux techniques urbains, n. 23-24, pp. 231-241, 1984, <https://www.persee.fr/doc/ aru_0180-930x_1984_num_23_1_1117>. Acesso em: 07 de dezembro de 2021.

FRIGOTTO, G.; CIAVATTA, M. Educar o trabalhador cidadão produtivo ou o ser humano emancipado? In : FRIGOTTO, G.; CIAVATTA, M, (Orgs.). A formação do cidadão produtivo: a cultura de mercado no ensino médio técnico. Brasília, DF: Inep, 2006, pp. 55-70.

FURIATI, N M de Á. Juventude e Estado no Brasil: a lógica constitutiva do Conselho Nacional da Juventude no Governo Lula. Brasília, DF, Tese de Doutorado em Sociologia. Programa de PósGraduação do Departamento de Sociologia, Universidade de Brasília, 340f., 2010.

GUATARI, F. Espaço e Poder: a Criação de Territórios na Cidade. Espaço e Debates, V, pp. 109-120, 1985. 
HAESBAERT, R, O mito da desterritorialização: do "fim dos territórios" à multiterritorialidade. 13. ed. Rio de Janeiro: Bertrand Brasil, 2004. ISBN: 978-8528610611. 396 p.

HARVEY, D. Condições pós-modernas. 6. ed. São Paulo: Edições Loyola, 1996.

HAYASHI, M. C.; HAYASHI, C. R.; MARTINEZ, C.M.. Estudos sobre Jovens e Juventude. Diferentes percursos refletidos na produção científica brasileira. Educação, Sociedade \& Culturas, $n^{\circ}$ 27, 2008, 131-154. Disponível em: <https://www.fpce.up.pt/ciie/revistaesc/ESC27/27_cristina.pdf> . Acessado: em 14 ago. 2015.

HOBSBAWN, E.. Os anos 60. In: Tempos Interessantes: uma vida no século XX. São Paulo: Companhia da Letras, 2002, p. 274-282.

LATOUR, B. Ciência em ação: como seguir cientistas e engenheiros sociedade afora. Trad. Ivone C. Benedetti São Paulo: Editora Unesp, 2000. ISBN: 85-7139-265-X.

LECHNER, N. Cultura juvenil y desarollo humano. JOVENes, Revista de Estudios sobre Juventud. Edición: año8, núm. 20. México, DF, enero-junio 2004, p. 12-26.

LEFEBVRE, H. De lo rural a lo urbano. 3. ed. Barcelona: Ediciones Península, 1975.

LOPES, A. S. Os lugares do urgente e do possível. Juventude, ativismos e movimentos sociais nas periferias urbanas: um estudo sobre a Zona Oeste da Cidade do Rio de Janeiro/ RJ. Rio de Janeiro, Tese de Doutorado em Políticas Públicas e Formação Humana. Programa de Pós-Graduação em Políticas Públicas e Formação Humana, Universidade do Estado do Rio de Janeiro, 185f., 2018.

MACHADO, L. O profissional tecnólogo e sua formação. Revista da RET, II, pp. 20-50, 2008.

MANACORDA, M.A.. Marx e a pedagogia moderna. 2. ed. Campinas: Editora Alínea, 2010. ISBN: 978-85-75164-07-5.

MARTINS, J.de S. As temporalidades da História na dialética de Lefebvre. In : MARTINS, J.de S. (Org.). Henri Lefebvre e o retorno à dialética. 1. ed. São Paulo: Editora Hucitec, 1996. pp.13-23. 151 p.

OLIVEIRA, F.G. Eletrificação e formação do patrimônio territorial da Light na cidade do Rio de Janeiro e no Médio Vale do Paraíba, Espaço e Economia, III, pp. 1-16, 2013.

OLIVEIRA, F.G. Reestruturação produtiva e inovação: novas redes técnicas e desigualdades sociais. In : GOMES, M.T. S.; TUNES, R. H.; OLIVEIRA, F. G. de (Orgs.). Geografia da Invocação: territórios, redes e finanças. 1. ed. Rio de Janeiro: Editora Consequência, 2021. pp. 207- 235.

ISBN: 978-65-87145-14-3. $524 \mathrm{p}$.

OLIVEIRA, F.G.; OLIVEIRA, L. D. Circuitos produtivos e a economia do petróleo no Estado do Rio de Janeiro: as transformações territoriais por ação dos níveis superiores da economia. Revista GeoUCE, VII, pp. 09-32, 2018.

OLIVEIRA, L.D. de; ROCHA, A.S. Neodesenvolvimentismo e reestruturação produtiva: O processo de reordenamento territorial no Oeste Metropolitano Fluminense (Rio de Janeiro, Brasil). In : PINA, H., et al. (Orgs.). Grandes Problemáticas do Espaço Europeu: Diversidade Territorial e Oportunidades de Desenvolvimento num Cenário de Crise. 1. ed. Porto: Fundação Universidade do Porto, 2014. pp. 126-142.

PESSANHA, R.de M.. Inovação, financeirização e startups como instrumentos e etapas do capitalismo de plataforma. In : GOMES, M. T. S.; TUNES, R. H.; OLIVEIRA, F. G. de (Orgs.). Geografia da Invocação: territórios, redes e finanças. 1. ed. Rio de Janeiro: Editora Consequência, 2021. pp. 433-467. ISBN: 978-65-87145-14-3. 524 p. 
RAFFESTIN, C.. Por uma Geografia do Poder. São Paulo: Ática, 1993. ISBN: 978-85-08042-90-6. OLIVEIRA, L.D.; GERMANDO, A. L.do N.; PINTO, M. A.do E. S. Crise, desenvolvimento e território: reflexões sobre o extremo oeste da Região Metropolitana do Rio de Janeiro. Revista Cadernos do Desenvolvimento Fluminense, XVIII, pp. 42-62, 2020.

RUFINO, M.. Redes Técnicas, territórios e escalas. Leituras sobre modernização e crítica da economia política do espaço. In : OLIVEIRA, F.G. de, et al. (Orgs.). Espaço e economia: geografia econômica e a economia política. Rio de Janeiro: Consequência, 2019.

SANTOS, J. M. dos. Paracambi: estudo de caso do processo de reconversão de uma fábrica de tecidos em "fábrica do conhecimento". Rio de Janeiro, Dissertação de Mestrado em Bens Culturais e Projetos Sociais, Programa de Mestrado Profissional em Bens Culturais e Projetos Sociais, Fundação Getúlio Vargas, 121f., 2017.

SANTOS, M.. A natureza do espaço. Técnica e tempo. Razão e emoção. São Paulo: HUCITEC, 1997.

SANTOS, M.. O retorno do território. OSAL: Observatório social de América Latina, XVI, pp. 251-261, 2005.

SCHUMPETER, J. A. (1911). Teoria do desenvolvimento econômico. São Paulo: Abril Cultural, 1982.

SOUZA, M..S. P.dos S. de. Os Institutos Federais de Educação, Ciência e Tecnologia como vetores de desenvolvimento no estado do Rio de Janeiro: a perspectiva de gestores de unidades. Revista brasileira de geografia econômica, XIV, pp. 1-17, 2019.

VALE, M. No terreno da "cidade inteligente": Geografias desiguais da inovação, do valor e do poder. In : GOMES, M. T. S.; TUNES, R. H.; OLIVEIRA, F. G. de (Orgs.). Geografia da Invocação: territórios, redes e finanças. 1. ed. Rio de Janeiro: Editora Consequência, 2021. pp. 21-37. ISBN: 978-65-87145-14-3. $524 \mathrm{p}$.

WILLIS, P.; TRONDMAN, M. Manifesto pela etnografia. Educação, Sociedade \& Culturas, n. 22.2008. p. 211-220.

WOOD, E. Democracia contra capitalismo: a renovação do materialismo histórico. São Paulo: Boitempo, 2011.

Sites Consultados:

SIGA GUANDU. Observatório. Rio de Janeiro, c2021, <http://www.sigaguando.or.br/ observatórioComite>. Acessado em 13 de março de 2021.

ANTF/Syster. PLANO ESTRATÉGICO FERROVIÁRIO DO ESTADO DO RIO DE JANEIRO ANTF RELATÓRIO P5 - Revisão Final CONSOLIDAÇÃO DA CARTEIRA PRELIMINAR DE PROJETO

<http://arquivo.proderj.rj.gov.br/setrans_pelc_imagens/SCSEditaImprensa/arquivo/upload/ Reltorio\%20P5\%20Revisao\%20Final.pdf>. Acessado em 24 de novembro de 2021.

\section{NOTAS}

1. DIAS, Leila Christina Duarte. Geografia e qualidade de vida: pensando as redes técnicas. Geosul, IX, pp. 7-15, 1994.

2. ${ }^{2}$ As verticalidades correspondem a "pontos no espaço que, separados uns dos outros, asseguram o global da sociedade e da economia"; as horizontalidades correspondem às "extensões formadas de pontos que se agregam sem descontinuidade, como na definição tradicional de região" (ibid. p. 255). A verticalidade apresenta-se como a expressão dos "vetores da modernização" e a horizontalidade como expressão "das ações localmente constituídas", 
possibilitando "uma base de vida que amplie a coesão da sociedade civil, a serviço do interesse coletivo" (Ibid., p. 228).

A "densidade técnica é dada pelos graus de artifício", em que a sua ausência estaria na "ecologia selvagem" (ausente de observação, inclusive remota) e sua plenitude como presença dos "objetos técnicos maduros"; a "densidade informacional", que "deriva, em parte, da densidade técnica", efetiva-se a partir da ação, já que a "informação apenas se perfaz com a ação" (ibid., id.); a densidade comunicacional refere-se ao "tempo plural do cotidiano partilhado" que "é o tempo conflitual da co-presença" (ibid. p. 205).

3. MANACORDA, Mario Alighiero . Marx e a pedagogia moderna. 2. ed. Campinas: Editora Alínea, 2010. ISBN: 978-85-75164-07-5.

4. SCHUMPETER, Joseph Alois (1911). Teoria do desenvolvimento econômico. São Paulo: Abril Cultural, 1982.

5. LATOUR, Bruno. Ciência em ação: como seguir cientistas e engenheiros sociedade afora. Trad. Ivone C. Benedetti São Paulo: Editora Unesp, 2000. ISBN: 85-7139-265-X.

6. "Ora o traço fundamental da governabilidade neoliberal é realizar a transformação de todas as relações sociais, portanto da relação dos homens com as coisas. Ela tem como singularidade a tendência a submeter sistematicamente a reprodução social em todos os seus componentes salarial, familiar, político, cultural, geracional, subjetivo - à reprodução ampliada do capital" (ibid.).

7. As aproximações dizem respeito às demandas e aos debates em torno do retorno no ramal Japeri - Barra do Piraí dos trens de passageiros (o Barrinha), e à possibilidade de reativação do ramal de Conrado- Miguel Pereira-Paty do Alferis. Contidos no Plano Estratégico Ferroviário do Estado do Rio de Janeiro (ANTF/Syster, 2021) como projetos vinculados ao turismo ferroviário. Há de observar que o uso desses ramais para transportes de passageiros, no período em que funcionaram, configurava-se como trens de ligação entre cidades em âmbito regional. No caso específico do ramal Paty do Aferis-Miguel Pereira-Conrado, iniciava-se em Japeri e o trajeto dos trens de passageiros se estendia até Três Rios. Nesses ramais, conectavam-se, por meio da circulação de mercadorias e indivíduos, economias, valores, modos de vida. Remetem a processos de modernização presentes na história desses ramais ferroviários.

8. Sobre a mobilidade urbana em âmbito metropolitano e o destaque dado ao modal ferroviário, vale citar a demanda identificada, por parte de professores e pesquisadores do Programa de Pós-Graduação em Geografia da Universidade Federal Rural do Rio de Janeiro (OLIVEIRA, GERMANO e PINHO, 2021), em torno da urgência quanto à criação de linha de passageiros ligando as cidades de Itaguaí à Japeri, passando pela cidade de Seropédica. Os autores observam que "a integração ferroviária da parte do extremo oeste, que atualmente transporta commodities" possibilita "transbordar para uma mobilidade ferroviária de passageiros, com a possível edificação de uma Estação Ferroviária Seropédica-UFRRJ, aproveitando os caminhos dos trilhos logísticos existentes para aproximar as populações locais" (ibid. p 57). A fundamentação apresentada expõe as contradições e dilemas referentes à mobilidade urbana em âmbito metropolitano e a relevância do modal ferroviário para esse fim.

9. Do conjunto de referências trabalhadas na tese, destaca-se: CARDOSO, Adalberto (2014). HAYASHI, Maria Cristina; HAYASHI, Carlos Roberto; MARTINEZ, Claudia Maria (2008). HOBSBAWN, Eric (2002). LECHNER, Nobert (2004). WILLIS, Paul; TRONDMAN, Mats (2008). 


\section{RESUMOS}

A presente comunicação aborda a construção de plano de pesquisas e estudos referentes à configuração da rede pública de formação tecnológica e os processos e políticas em torno do desenvolvimento em âmbito regional/local. Identifica-se o significado atribuído a essas unidades de ensino como potenciais vetores de desenvolvimento e polos de inovação. As formulações a serem apresentadas derivam de inquietações desenvolvidas nas atividades docentes na Faculdade de Educação Tecnológica do Estado do Rio de Janeiro (FAETERJ), campus Paracambi, nos cursos de Tecnólogo em Gestão Ambiental e Tecnólogo em Sistema da Informação. Tais formulações vinculam-se à agenda de debates e reflexões no âmbito do grupo de estudos Redes Técnicas e Linhas Cruzadas. Trata-se de uma geografia sobre a rede de formação tecnológica diante do desenvolvimento em seus processos e expressões no território; como também sobre o estudante em sua condição e perspectivas de futuro. $O$ que se expõe são apontamentos que embasam esse plano de investigação. Contextualiza-se, incialmente, o lugar em que se situa a FAETERJ Paracambi: a antiga fábrica têxtil que hoje é designada como Fábrica do Conhecimento. Delineamentos conceituais e metodológicos são apresentados, destacam-se os conceitos de território e redes técnicas. Posteriormente, são expostas compreensões sobre as possibilidades e entraves presentes na formação tecnológica; o que se desdobra no trato sobre as perspectivas analíticas referentes à correspondência entre desenvolvimento e inovação. Por fim, apresentamse, de forma breve, percursos investigativos que se ensejam e que estão em andamento

The present paper addresses the development of research plans and studies regarding the setup of the public system of education in technology, and the processes and policies around the development at regional/local level. The significance of such teaching units, acting as leading actors in the development of technologies and as hubs of innovation, is identified. The formulations to be presented arise from concerns sprung from the teaching experience carried at the College for Technological Studies of Rio de Janeiro (FAETERJ), campus of Paracambi, in the courses of Technologist in Environmental Management and Technologist in Information Systems. Such formulations relate to the current debate ongoing at the Redes Técnicas e Linhas Cruzadas. It is about a geography about the technological formation network in face of the development in its processes and expressions in the territory; as well as about the student in their condition and future prospects. What is hence presented are notes that support this research plan. It begins by contextualizing the place where FAETERJ Paracambi is located: the former textile factory which is now called the Factory of Knowledge. Conceptual and methodological outlines are presented, highlighting the concepts of territory and technical networks. Subsequently, readings on the possibilities and obstacles observed in technological training context are presented. This unfolds in the treatment of analytical perspectives concerning the correlation between development and innovation. Finally, a brief presentation is made of the investigative paths that are envisioned and which are in progress.

A partir du cas de la Faculté d'Éducation Technologique de l'État de Rio de Janeiro (FAETERJ), campus Paracambi, l'article suivant est un esquisse d'un projet de recherche sur le réseau publique de formation technologique et les politiques de développement local et régional. En s'appuyant sur les concepts de territoire et de réseaux techniques, on présente d'abord la transformation d'une ancienne usine textile vers un campus technologique appellée Usine de la Connaissance. Ensuite, on discute les possibilités et les obstacles liés à la formation technologique des étudiants afin de réflechir sur les rapports entre développement et innovation. 
Esta comunicación aborda la construcción de un plan de investigación y estudios sobre la configuración de la red pública de formación tecnológica y los procesos y políticas en torno al desarrollo a nivel regional / local. Se identifica el significado atribuido a estas unidades didácticas como potenciales vectores de desarrollo y polos de innovación. Las formulaciones a presentar derivan de inquietudes desarrolladas en las actividades docentes de la Facultad de Educación Tecnológica del Estado de Rio de Janeiro (FAETERJ), campus Paracambi, en los cursos de Tecnólogo en Gestión Ambiental y Tecnólogo en Sistemas de Información. Dichas formulaciones están vinculadas a la agenda de debates y reflexiones en el ámbito del grupo de estudio Redes Técnicas y Líneas Cruzadas. Se trata de una geografía sobre la red de formación tecnológica frente al desarrollo de sus procesos y expresiones en el territorio; así como sobre el alumno en su condición y perspectivas de futuro. Lo que se expone son notas que apoyan este plan de investigación. Inicialmente, contextualiza el lugar donde se ubica FAETERJ Paracambi: la antigua fábrica textil que hoy se designa como la Fábrica del Conocimiento. Se presentan esquemas conceptuales y metodológicos, se destacan los conceptos de territorio y redes técnicas. Posteriormente, se explican los entendimientos sobre las posibilidades y obstáculos presentes en la formación tecnológica. Qué se despliega al abordar las perspectivas analíticas sobre la correspondencia entre desarrollo e innovación. Finalmente, se presentan brevemente los caminos de investigación que se están emprendiendo y que están en curso.

\section{ÍNDICE}

Keywords: technological training; development; innovation; territory; technical networks. Palabras claves: formación tecnológica; desarrollo; innovación ; territorio ; redes técnicas. Palavras-chave: formação tecnológica; desenvolvimento; inovação; território; redes técnicas. Mots-clés: formation technologique ; développement ; innovation ; territoire ; réseaux techniques.

\section{AUTOR}

\section{ARTUR SÉRGIO LOPES}

Geógrafo. Mestre em Geografia, pela Universidade Federal Fluminense, Programa de PósGraduação em Geografia (UFF/PPGEO). Doutor em Políticas Públicas e Formação Humana, pelo Programa de Pós-Graduação em Políticas Públicas e Formação Humana, Universidade do Estado do Rio de Janeiro (UERJ/PPFH). Professor na Faculdade de Educação Tecnológica do Estado do Rio de Janeiro, campus Paracambi (FAETERJ, Paracambi). E-mail: rutraoigres@yahoo.com.br 